\title{
Conquering space and time \\ The challenge of emissions from land use change
}

Naomi Pena, Neil Bird, Dorian Frieden and Giuliana Zanchi

\section{Key points}

- The EU Renewable Energy Directive (EU-RED) abandons the Kyoto Protocol restriction of responsibility for greenhouse gas emissions to those occurring within national borders, it makes EU bioenergy users responsible for supply-chain emissions throughout the world.

- However, problems arise from the EU-RED's continuation of the Kyoto Protocol land-typesplus-activities approach and disregard for the time lag between emissions from forest-sourced biomass and compensating removals of $\mathrm{CO}_{2}$ from the atmosphere.

- The land-types-plus-activities approach leads to omissions, such as emissions from forests that remain forests. While not a major issue for biofuels, this seriously underestimates the $\mathrm{CO}_{2}$ profile of forest-sourced biomass for heat and power.

- The EU-RED's failure to address the time lag means that bioenergy approved by EU-RED can be used to meet targets even though significant increases in emissions occur during the time horizon of the targets.

- These problems can be resolved through a well-designed eligibility formula. A formula covering timing of increases and losses in all carbon pools would ensure that bioenergy reduces greenhouse gas emissions without needing to prohibit actions on specific land types.

\section{Overview}

In April 2009, the European Union agreed on a Renewable Energy Directive (EU-RED). This directive establishes an overall EU target for 2020 of 20\% renewable energy and targets of $10 \%$ renewable energy in the transport sector of each Member State (EU 2009). According to estimates used by the EU's Directorate of Transportation and Energy, 195 Mtoe (million tonnes of oil equivalent) of biomass will be needed to meet these targets (Ragwitz et al. 2009), a doubling of the current use of biomass. Some 173 Mtoe of the needed biomass is expected to come from EU sources, with the remaining 22 Mtoe supplied by imports.

The EU-RED provides criteria that determine the eligibility of biofuels to meet renewable energy obligations. The criteria address two sustainability issues: biodiversity and greenhouse gas (GHG) emissions. GHG concerns are addressed through two overlapping sets of criteria: prohibitions on use of biomass from lands with high carbon stocks and determination of GHG emissions along the biomass value chain.

The GHG determinations must demonstrate that a biofuel consignment achieves savings of $35 \%$ compared to the fossil fuels it will replace in order for the consignment to be used to meet the EU-RED targets. ${ }^{2}$ The formula used to calculate GHG profiles includes a term for emissions resulting from land conversion. Thus prohibitions on land conversion, insofar as they are intended to address GHG concerns, are redundant with the GHG determination 
because the GHG emissions from such conversion are already included in the formula. This inclusion ensures that no biofuel where the biomass originates from land conversions, resulting in high GHG emissions, could qualify.

The EU-RED is designed to reduce GHG emissions from the energy and transport sectors and thus help EU Member States achieve their targets under the Kyoto Protocol. Its approach represents a significant improvement over the Kyoto Protocol. The EU-RED significantly extends accounting for emissions due to the use of biomass for energy. It accomplishes this by abandoning the Protocol's limitation of responsibility for GHGs within national borders. Under the EU-RED, users take responsibility for emissions occurring along the full value chain of biomass production regardless of where they occur. This consumer-based accounting (CBA) approach addresses some of the spatial accounting gaps of the Kyoto Protocol.

For example, the Kyoto Protocol does not include emissions from land use or management changes in non-Annex I countries, neither does it mandate inclusion of emissions due to management changes in Annex I countries. The EU-RED, in contrast, counts both emissions from direct land use changes in non-Annex I countries and those from management changes on agricultural lands used to produce biomass for biofuels.

Neither the EU-RED nor the Kyoto Protocol require countries to account for carbon stock losses due to management changes in forests (forests remaining forests, though some Annex I nations voluntarily do so). The formula for GHG determination under the EU-RED lacks a term for these changes. Thus, emissions and removals due to forest management-and in particular the lag between biomass removals and recovery of forest carbon stocks - do not enter into determinations of whether a bioenergy consignment is eligible to meet EU-RED targets. Carbon neutrality (CN) factors can be used to address this problem.
The EU-RED attempts to address another accounting gap of the Kyoto Protocol, namely, emissions due to indirect land use change in non-Annex I countries. The mechanism used is an incentive for biomass produced on restored degraded lands, with the objective to reduce indirect land use change. The effectiveness of this method is open to question. It is possible that extending the CBA approach to cover all internationally traded biomassbased goods - food and feed, as well as all wood and fibre products-would provide a more effective means to address indirect land use change. However, as this is a new concept, further analysis and research would be needed to determine its consequences.

Since key features of the EU-RED have their origin in Kyoto Protocol rules, this brief starts by reviewing the similarities and differences between the EU-RED and the Kyoto Protocol. It then discusses the pros and cons of EU-RED approaches and identifies issues still to be addressed.

\section{The EU-RED and the Kyoto Protocol: Similarities and differences}

The EU-RED adopted the Kyoto Protocol approach to the land sector, while attempting to overcome some of the perverse incentives created by the Protocol's bioenergy accounting rules. Thus, it is critical to understand Kyoto Protocol approaches to land and bioenergy and their problems in order to evaluate the EU-RED and move it forward.

\section{Similarities}

Especially during the early stages of its development, the Kyoto Protocol focused on land use change. It defined specific human activities that result in changes to forests. Article 3.3 of the Protocol requires that Parties include emissions and emission reductions from afforestation, reforestation and deforestation in their calculations determining target compliance. This approach requires defining 'forest', 'deforestation', 'afforestation' and 'reforestation'. 
The EU-RED uses the same approach. It prohibits use of biomass originating from lands converted from one land category to another, thereby prohibiting conversion from a land with high carbon stocks to one with low carbon stocks. In the case of forests, a minimum of 30\% crown cover is used to define when a forest qualifies as 'high carbon stock'. The EU-RED also prohibits biomass from converted wetlands or undrained peatlands, land categories that do not yet appear in the Kyoto Protocol. Finally, the EU-RED prohibits use of biomass from 'natural forest' and 'high-biodiversity grasslands' and defines these two land uses.

The EU Emission Trading System (EU-ETS) also shares the Kyoto Protocol's accounting approach, which is based on United Nations Framework Convention on Climate Change (UNFCCC) reporting. Under UNFCCC reporting, carbon stock losses are reported in the nation in which they occur. To avoid double counting, no emissions are attributed to combustion of biomass in the energy sector (Eggleston et al. 2006) - an emission factor of ' $O$ ' is applied to emissions from combustion of biomass.

Since virtually every nation reports under the UNFCCC, reporting carbon losses within national borders, and not attributing emissions to combustion of biomass, results in virtually full coverage of emissions due to carbon stock losses worldwide. However, since only Annex I nations report under the Protocol, carbon stock losses due to land use or management changes in non-Annex I countries are not included. This creates a perverse incentive to encourage more use of biomass for energy in Annex I nations than would occur if (a) bioenergy $\mathrm{CO}_{2}$ emissions had a factor of ' 1 ' or (b) carbon stock losses outside those reported under the Kyoto Protocol had to be accounted for. Under this system, bioenergy can also be used to achieve targets under circumstances that, worldwide, result in increased rather than decreased emissions. Since implementation of the Kyoto Protocol, these negative consequences have become a source of concern (e.g. Searchinger et al. 2009), and the EU-RED represents an important step towards addressing them.

\section{Differences}

The EU-RED's approach to biofuels attempts to redress the negative consequences that arise from the Kyoto Protocol accounting system by including carbon stock losses not accounted for under the Protocol. It includes emissions from direct land use and agricultural management changes throughout the world. The EU-RED requires reporting on emissions due to cultivation (including direct land use change, if any), processing and transport of biofuels, regardless of where they occur. Emissions along this entire value chain are used to determine whether a biofuel consignment can be used to satisfy the renewable obligation. This approach is referred to as 'consumerbased accounting' to distinguish it from the Kyoto Protocol's national-borders approach. Under CBA, users of products are responsible for all emissions 'embedded' in the product.

The EU-RED also attempts to address emissions from indirect land use change. Land use changes are referred to as indirect changes when they occur beyond the boundaries of a site where production has been switched from food, feed or fibre to biomass for energy. Such indirect land use changes are caused by market signals -increased commodity prices or unmet demand for feed, food or fibre products. The extent of GHG emissions caused by indirect land use changes is a subject of considerable controversy (Farrell and O'Hare 2008, Searchinger et al. 2008, Cherubini et al. 2009, Hertel et al. 2009, Sheehan 2009). Concern is sufficiently widespread that the EU-RED tries to address these emissions.

To reduce indirect land use change, the EU-RED formula includes an incentive for biomass sources from degraded lands: a $29 \mathrm{~g} \mathrm{CO}_{2} / \mathrm{MJ}$ reduction in the GHG profile of the biomass consignment. The idea behind this incentive is that growing biomass on lands not previously cultivated avoids reducing supply and thus avoids market signals leading to indirect land use change. It remains to be seen whether the EU-RED incentive will result in significant use of degraded or contaminated lands, as rehabilitation of these lands is both costly and difficult. 
The EU-RED recognises that currently there is no agreedon methodology to address indirect land use changes. As a result, the European Commission was requested to provide a proposal 'containing a concrete methodology for emissions from carbon stock changes caused by indirect land use changes' (EU 2009) to accompany its 2010 report, if appropriate.

In adopting the CBA approach, the EU-RED was confronted with an issue that does not arise under the Kyoto Protocol: what time period to use in accounting for emissions due to carbon stock changes. This issue does not arise in the Kyoto Protocol because Annex I nations count emissions in the commitment period during which they occur. The current EU-RED rules are designed for biofuels, for which most of the biomass comes from annual crops, at least currently. Under these conditions, there is no significant time lag between $\mathrm{CO}_{2}$ emitted from use of the biomass and removal of an equivalent amount of $\mathrm{CO}_{2}$ from the atmosphere through regrowth. The only emissions with longer payback periods are those from land use and management changes, and the EU-RED formula for determining compliance includes terms to cover these emissions over a 20-year period. However, the lag between emissions from use of wood-based biomass and recovery through regrowth can be significantly longer.

\section{Evaluation of EU-RED elements: Problems and potential solutions}

The current EU-RED uses a combination of:

- Consumer responsibility

- Specified land types, land-type changes and prohibited actions

- A formula to determine GHG profiles of biomass consignments that lacks a timing factor appropriate to forest-sourced biomass.

\section{Consumer responsibility using the CBA approach}

The EU-RED CBA approach removes significant spatial accounting gaps that arise in the Kyoto Protocol and holds potential to address further gaps. It takes into account emissions in non-Annex I countries that result from production and transportation of biomass or biofuels in calculating targets achieved. This is an important step forward from Kyoto Protocol accounting, under which emissions in non-Annex I nations do not enter the accounting system.

It is important to recognise that CBA benefits are achieved through abandoning one of the foundations of the Kyoto Protocol: restricting responsibility for emissions to those occurring within national boundaries. The EU-RED adopts a quite different policy framework: user responsibility for emissions. This harnesses the power of consumers to increase the market share of low-emission products. However, while future international agreements may incorporate CBA approaches, the EU-RED system currently operates within the context of the Kyoto Protocol. Thus, biofuels that satisfy EU-RED requirements based on CBA also enter systems-Kyoto Protocol and EU-ETS obligations - in which bioenergy emissions have a zero emission factor. As a result, much of the benefit of the EU-RED is lost, because supply-chain emissions reported for EU-RED eligibility are not counted in meeting Kyoto Protocol or EU-ETS obligations.

CBA is gaining attention for a number of reasons, one of which is the increasing role of international trade. International trade is growing significantly more rapidly than other macro-variables that drive global emissions (see Figure 1) (Peters et al. 2009). CBA can be applied to all internationally traded goods, and thus it has applications far beyond bioenergy. If applied across key internationally traded products, a CBA approach could bring a substantial proportion of emissions in non-Annex I nations into a compliance system, without requiring them to accept $\mathrm{GHG}$ limitations. Applying CBA to all internationally traded biomass-based products would also account for all indirect land use change attributable to use of biomass by nations with GHG obligations. 


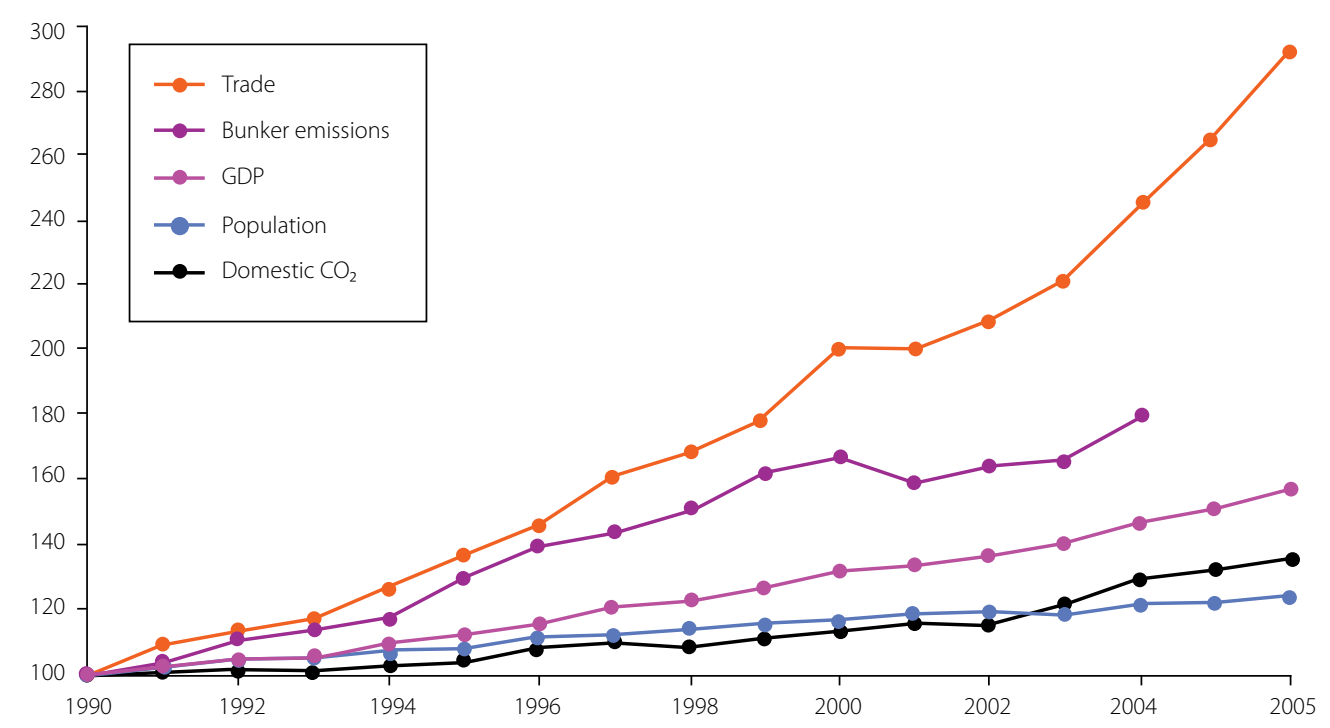

Figure 1. Factors driving GHG emissions: growth in key macro-economic variables since 1990

Note: GDP and trade are calculated in constant US dollars.

Source: Peters et al. (2009)

\section{Specified land types and prohibited actions: lessons from the Kyoto Protocol}

The land-type and prohibited-actions approach has significant weaknesses, and it is considerably less accurate in terms of GHG emissions than a well-designed CBA formula. This approach requires definitions that are difficult to reach agreement on and has a tendency to omit actions and land types that are later seen to be significant sources of GHGs.

\section{Kyoto Protocol versus EU-RED goals}

Kyoto Protocol accounting is intended to support national caps on emissions, whereas the EU-RED is focused on determining the eligibility of consignments of biomass-for-energy or biofuels to meet the EU's renewable fuel obligation. Therefore, it is appropriate to consider the suitability of the Kyoto Protocol when applied to the EU-RED. The history of the Kyoto Protocol suggests that most of the reasons for using this approach do not apply to the EU-RED and that the approach suffers from the difficulty of defining land types.
In the Kyoto Protocol, the land-use-change approach was adopted to limit the extent to which changes in forest biomass contributed to meeting targets. This limited approach served a number of purposes (Benndorf et al. 2006):

- achieving a compromise between stakeholders who wanted to exclude the land sector from the Kyoto Protocol and those who supported its inclusion,

- alleviating uncertainties caused by the sparse knowledge most nations possess regarding land-sector emissions (Schlamadinger and Marland 2000),

- reducing the potential for inequalities in ease of target compliance due to widely differing forest circumstances among Parties.

Of these issues, only one is shared by the EU-RED: the need to find a compromise between stakeholders. In the case of the EU-RED, the compromise is primarily between stakeholders focused primarily on climate mitigation and use of bioenergy for various purposes and those whose primary goal is preservation of ecosystems. However, 
calculation of GHG profiles is the most accurate tool for achieving climate mitigation, while payments - or offers of debt relief, technology transfer, concessions under the WTO, etc.- - are likely to be more effective in achieving preservation.

\section{Defining land types}

In both the Kyoto Protocol and the EU-RED, defining actions requires defining land types or categories. This was a difficult process under the Kyoto Protocol, where a forest had to be defined to determine what constitutes afforestation, reforestation and deforestation. In the case of the EU-RED, attempts are made to define lands of high carbon stocks and high biodiversity. The EU-RED approach to GHG sustainability is, appropriately, based on the concept that use of biofuels should result in GHG savings compared to the fossil fuels they replace. To achieve this, in addition to the formula for calculating a biofuel's GHG profile, it is stated that land should not be converted where the carbon stock losses could not, within a reasonable period, be compensated by the GHG savings (EU 2009, paragraph 73). Article 17 prohibits biomass obtained from conversion of lands with high carbon stocks, defining such lands as wetlands and forested areas with 30\% or more canopy cover.

It is unclear why the $30 \%$ crown cover was chosen. Experts in the field point out that forest inventories measure biomass but do not collect data on crown cover. While biomass can be converted to carbon stocks, the fact that crown-cover data are not collected means that information on the correlation between crown cover and carbon stocks is lacking. For example, a tropical dry deciduous forest with $40 \%$ crown cover has very different carbon stocks from a moist tropical forest with 40\% crown cover (Brown personal communication). At the same time, some forests with over $30 \%$ crown cover are undoubtedly high in carbon stocks, but not all are. Thus, it is possible that, for example, use of biomass from conversion of some forests with 30\% crown cover could achieve the stipulated savings of 35\% with respect to fossil fuels.

\section{Tendency towards omissions}

The history of the Kyoto Protocol suggests a second concern with the land-type and specified-actions approach: new land categories and activities continue to be defined, re-opening discussions on land types and activities that should be included. Wetlands, peatlands, peatland drainage and various categories of grassland are current examples in Kyoto Protocol discussions. Similar difficulties will emerge under the EU-RED if it continues with the land-type, specified-actions approach.

The rule that biomass cannot come from forests that had 30\% canopy cover as of 2008 but no longer have that status fails to account for significant potential GHG emissions. Selective harvesting can occur in forests with $50 \%$ or more crown cover without reducing crown cover below $30 \%$. In such cases, there would be no change in the forest's 'above $30 \%$ crown cover' status, and the biomass could be used under the EU-RED. The EU-RED formula does not include a term covering emissions due to carbon stock losses on lands whose status does not change. Consequently, emissions from harvesting in forests that remain 'forests' would not be included in a biomass consignment's GHG profile.

This also means that losses due to removal of biomass residues are not considered. The EU-RED formula lacks terms for both changes in live wood stocks and changes in dead wood stocks in forests remaining forests (see Bird et al. 2009 for further details). However, use of residues for energy is a very attractive option, since it increases the efficiency of use of both land and biomass. Importantly, it is the only bioenergy option that avoids pulling currently used biomass from high-priority markets, such as food, feed and wood products. Thus, use of residues avoids triggering issues of competition and indirect land use changes, both of which have been attributed to use of biofuels (Pena 2009).

Finally, the EU-RED formula may not include carbon stock increases other than those resulting from improved management of agricultural soils. The relevant term refers 


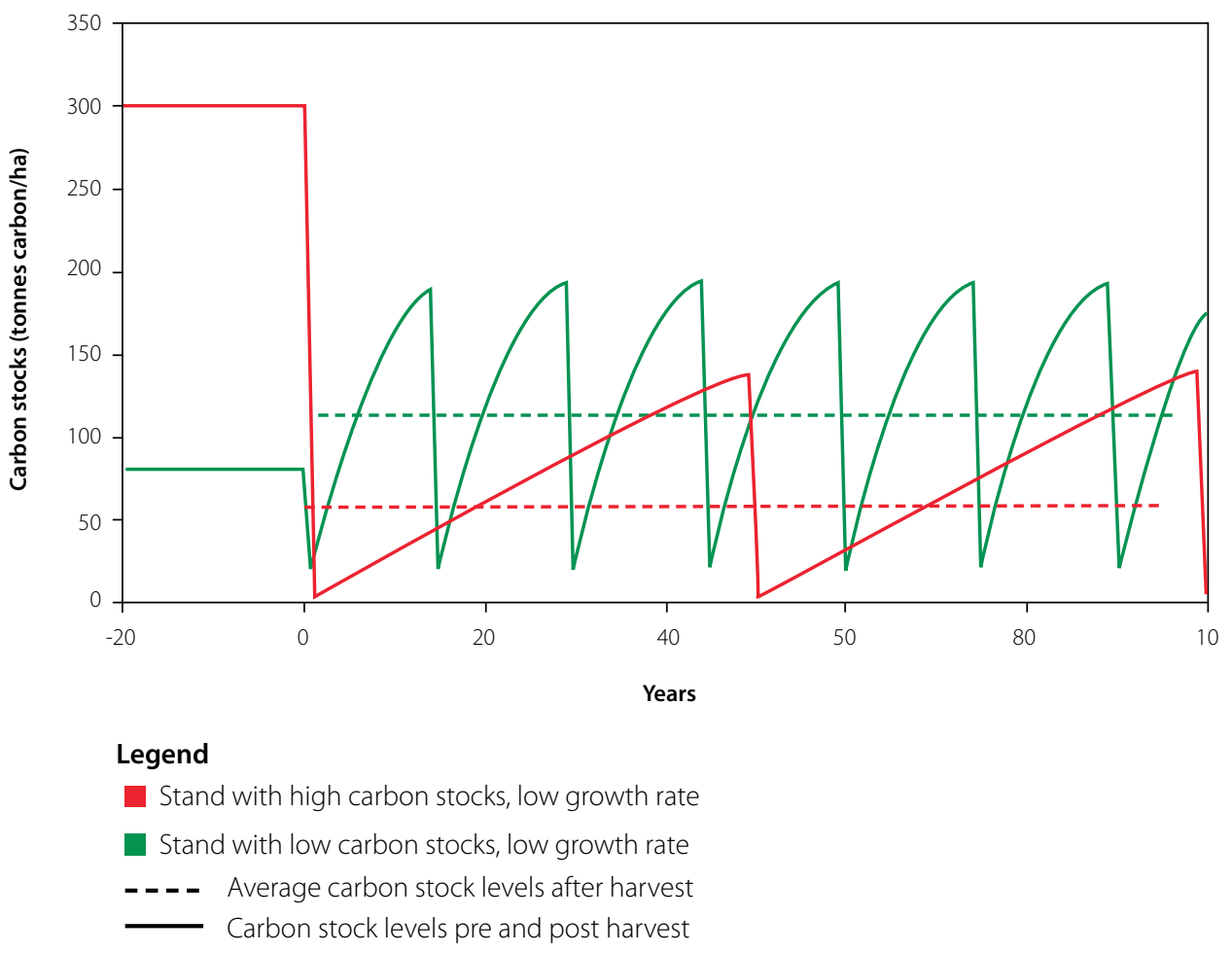

Figure 2. Average carbon stock levels compared to pre-harvest levels: Two theoretical cases

to 'emissions from carbon stock changes'. Unless this is interpreted to mean both emissions and removals, no credit would be given for increasing above-ground carbon stocks, as would occur with conversion of grasslands or annual crops to plantation. If the term covers both positive and negative emissions, the EU-RED formula would account for about half of the carbon stock increases achieved by, for example, conversion of grassland to plantations (Bird et al. 2009). This low estimate of the benefits of conversion to plantations results from not including dead above-ground stocks and limiting the period over which emissions from land use change must be calculated to 20 years, which is not long enough for full recovery of soil carbon after plantation establishment. If the formula does not include removals, only about $10 \%$ of carbon stock gains would be covered.

\section{The land-type approach and EU-RED goals}

The EU-RED land-type approach results in a poor correlation between prohibited activities and their GHG impacts, moreover, it is difficult to implement on the ground. Thus, it serves neither climate mitigation nor ecosystem preservation goals effectively.

This lack of correlation between prohibited activities and GHG impacts results from the wide variety in per-hectare carbon stocks and growth rates around the world. Biomass in forests varies from 50 tonnes per hectare ( $\mathrm{t} / \mathrm{ha}$ ) to 660 $\mathrm{t} / \mathrm{ha}$, and growth rates vary from $1 \mathrm{t} / \mathrm{ha}$ per year to more than 20 t/ha per year (Eggleston et al. 2006). While this range covers forests with from 10\% to 100\% canopy cover, the range in forests with over $30 \%$ canopy cover is still likely to be in the order of five- to six-fold. Thus, the GHG impact of the prohibition may be five to six times as high in one case as in another.

Figure 2 illustrates the very different GHG impacts that could occur for clear-cutting and re-growing highcarbon-stock, low-growth-rate forest (red lines) versus clear-cutting a lower-carbon-stock forest and replanting 
it with a high-growth-rate species (green lines). In the first case, clear-cutting and re-growing would result in average carbon stocks considerably below the original level. However, it is important to understand that as long as the forest is allowed to re-grow-as long as its status as forest land is unchanged and it still has the potential to reach $30 \%$ crown cover-the EU-RED would not prohibit use of its biomass since there is no land use change.

In the second case, after replacing a lower-carbon-stock forest with fast-growing species, average carbon stocks are well above original levels. From a climate-change mitigation perspective, actions of this type should be encouraged (given that the initial stock would not increase considerably). However, the lack of clarity as to whether the 'land use change' term includes carbon stock increases (removals), together with lack of clarity as to whether a plantation qualifies as forest, ${ }^{3}$ means that the EU-RED may prohibit use of biomass from such activities.

The land-type approach may well fail to achieve biodiversity protection objectives. The EU-RED endeavours to avoid encouraging destruction of biodiverse lands (EU 2009, paragraph 69) by prohibiting use of biomass from lands with 'high biodiversity'. The EU-RED translates this objective into prohibitions on sourcing biomass from:

- Forest and other wooded land of native species where there is no clearly visible indication of human activity and the ecological processes are not significantly disturbed,

- Grassland that would remain grassland in the absence of human intervention and that maintains its natural species composition and ecological characteristics and processes.

Few if any forests in the northern hemisphere have no visible indications of human activity, and humans are active in large portions of southern hemisphere forests, including those generally considered to be high-biodiversity reservoirs. In fact, the criteria have an apparent bias against sourcing biomass from southern hemisphere forests, raising questions as to their equity.
What constitutes natural species is also controversial, given forecast climatic changes, in many instances the case could be made that grasslands will cease to be grasslands even in the absence of other human intervention. Thus, it can be questioned whether, in practice, the criteria will actually protect the target lands. In any event, it is likely that protection will require considerable research and stakeholder processes. Thus, the definitions will not provide clear or easily implemented guidance.

Given these realities, use of land types is unlikely to 'prevent unnecessary, burdensome research by economic operators' (EU 2009, paragraph 73) —one of the justifications of the approach - in the case of biodiversity protection. The poor correlation between prohibited actions and GHG results, as well as problems stemming from omissions could be resolved through improving the current EU-RED formula used to determine eligibility. Terms could be used that would cover increases and losses in above-ground and below-ground, dead and live carbon pools. Knowledgeable project developers would not need to undertake sophisticated calculations to know that application of such a formula would result in biomass profiles well in excess of the $35 \%$ standard if biomass were sourced from wetlands or from conversion of forests with high carbon stocks to other land uses. If timing of these changes were included in conjunction with terms covering all sources of carbon gains and losses, prohibitions based on land type would not be needed to ensure achievement of climate goals.

\section{Timing of forest-sourced emissions}

Even before implementation of the Kyoto Protocol, scientists pointed out that, in the case of biomass from forests, time lags can be significant between the release of $\mathrm{CO}_{2}$ through its combustion and recapture of an equivalent amount of $\mathrm{CO}_{2}$ from the atmosphere through regrowth (Schlamadinger and Marland 1996). The Kyoto Protocol focuses on emissions in Annex I countries, and to the extent that Parties must account for losses of forest biomass, they would account for losses in the same year as, or prior to, its use for bioenergy. 


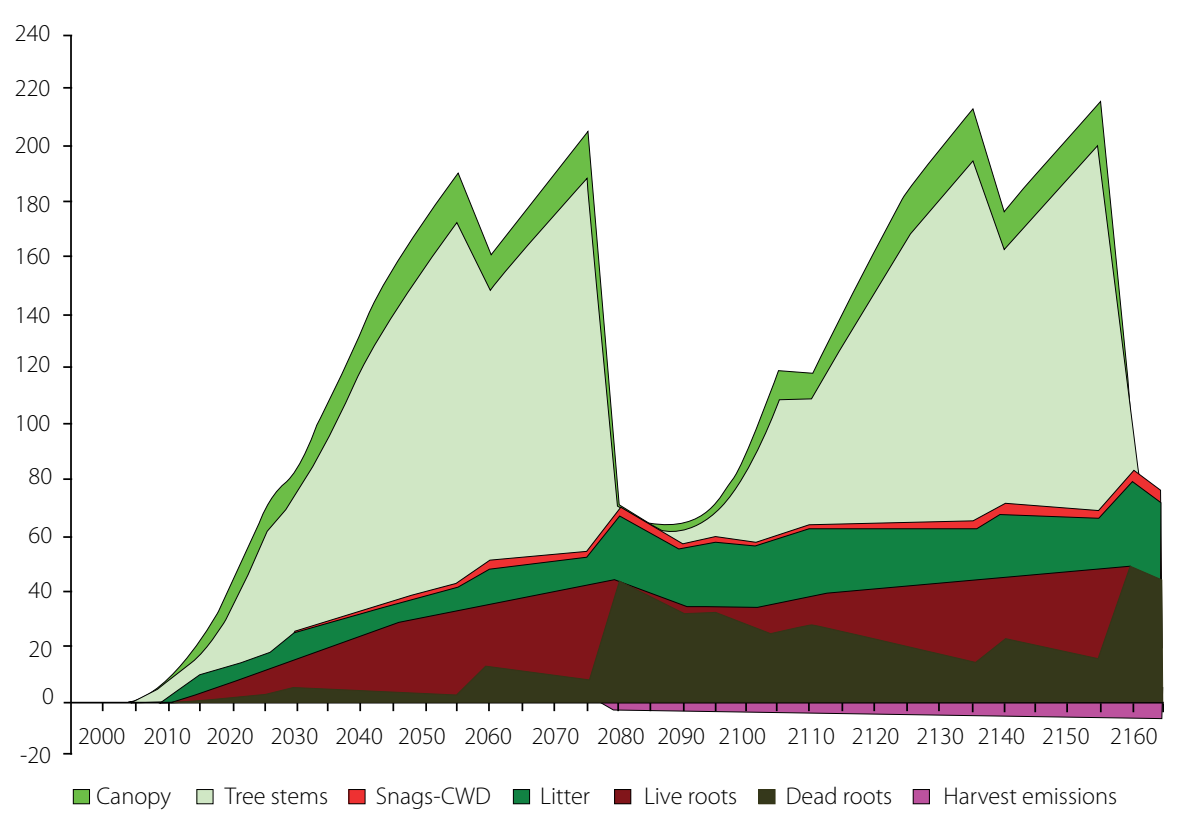

Figure 3. Changes in carbon pools over time after harvest: 80 -year rotation forest Source: Manriquez (2002)

However, the EU-RED extends responsibility for emissions to countries that only report under the UNFCCC. As in the case of spatial coverage, the instruments use different time horizons. The UNFCCC is not concerned with achievement of near-term targets. However, insofar as the EU-RED is part of a system designed to reduce emissions within a 2020 time horizon, the timing of removal of $\mathrm{CO}_{2}$ from the atmosphere in relation to $\mathrm{CO}_{2}$ emitted during combustion is an important issue. This relationship-the extent to which removals compensate for emissions within target time frames-determines whether or not use of biomass for energy assists is reducing or increasing emissions within target time frames.

In the case of woody biomass, the time required for carbon stocks to fully recover from harvest will, in many cases, exceed the time horizon of targets relevant for the EU-RED. In the case portrayed in Figure 3, for example, carbon stocks do not recover to pre-harvest levels for about 50 years. However, if harvested material is used for bioenergy, the carbon emissions will occur as soon as the wood is combusted, in or shortly after the harvest year (2080 in the figure).

As discussed previously, EU-RED rules allow removal of wood from forests that remain forests. Thus, biomass used to meet EU-RED targets can come from forests where regrowth would not compensate for emissions until well beyond 2020.

The magnitude of the problem could be reduced by using a factor of ' 1 ' instead of ' 0 ' for $\mathrm{CO}_{2}$ from biomass combustion. However, as shown in Figure 3, carbon losses also occur in other pools with long recovery rates, such as the dead roots pool. Carbon neutrality factors take into account all the losses and recovery periods and are highly compatible with the CBA.

Like the EU-RED's CBA approach, CNs operate along the full value chain. CNs include terms covering emissions due to cultivation, land use change, processing and transport. The term(s) in a CN calculation covering carbon stock 
gains and losses $\left(\mathrm{CN}_{C}\right)$ includes all sources of gains and losses - above and below ground, live and dead biomass - and calculates the extent of GHG emissions savings as of a specified time.

Carbon neutrality factors, defined by Schlamadinger et al. (1995), quantify the extent to which use of biomass reduces emissions compared to a replaced fossil fuel. For example, a CN of $60 \%$ as of a specific year means that applying ' 0 ' as a factor to $60 \%$ of the biomass emissions and a factor of ' 1 ' to the rest would result in accounting corresponding to actual savings. ${ }^{4}$ The $\mathrm{CN}^{\prime} \mathrm{s}$ time feature can be used to establish the GHG savings of use of biomass during the time horizon of specified targets. Although the time until complete recovery of carbon stocks can greatly exceed the time horizon of a target, at much shorter time intervals use of woody biomass can result in reduced emissions compared to fossil fuels. The $\mathrm{CN}$ measures the extent to which this is the case.

For example, within a 20-year time horizon, use of forest residues could have a $\mathrm{CN}$ in the range of $60 \%$, while biomass from harvests in European forests could result in negative $\mathrm{CN}$ factors. A negative $\mathrm{CN}$ factor indicates that carbon losses are resulting in more emissions to the atmosphere than would use of the target fossil fuel. New plantations could have $\mathrm{CN}$ factors above 1, indicating that net removals of $\mathrm{CO}_{2}$ from the atmosphere are greater than the emissions from combustion of the biomass (Zanchi personal communication).

Use of CN factors would also resolve a lack of clarity in the EU-RED as to what constitutes a 'reasonable length of time' for recovery of carbon stocks (EU 2009, paragraph 73). No pre-determined length of time for improvement over fossil fuels would be required, and it might be appropriate to allow use of bioenergy consignments that resulted in, for example, at least $10 \% \mathrm{GHG}$ savings compared to the fuel it was replacing within the target period.

\section{Conclusion}

In its current form, the EU-RED approach widens the spatial reach of responsibility for $\mathrm{GHG}$ emissions. By doing so, it partially addresses the Kyoto Protocol's spatial accounting gap. However, the EU-RED fails to address gaps due to use of biomass from lands remaining in their current use category within or outside the EU. The improvement in spatial accounting is not accompanied by a corresponding improvement in accounting for the time lag between combustion emissions and regrowth of woody material. Through its focus on near-term achievements based on use of biomass and responsibility for emissions caused by its use worldwide, the EU-RED raises the importance of time lags while failing to provide a mechanism to address them.

The current EU-RED formula for determining biomass GHG profiles lacks terms for some critical sources-harvests and extraction of residues in forests remaining forests. Without such terms, replacement of fossil fuels with biomass can result in target compliance-targets partially designed to achieve GHG reductions - while increasing emissions. Due to the long recovery rates of woody biomass and other carbon pools, time-dependant terms may useful.

Finally, the intention of the EU-RED is to include responsibility for emissions in non-Annex I as well as Annex I countries. In this context, the realities of the global GHG impacts of the EU-RED approach are of considerable concern. To the extent that the EU-RED contributes to achieving EU targets at the cost of causing global increases that may last for many decades or centuries, changes to the approach should be considered.

\section{Endnotes}

1 In early 2010, the directorate was split into a Directorate of Energy (DG Ener) and a Directorate of Mobility and Transport (DG MOVE). 
2 Starting in 2017, savings must be 50\%, or 60\% in the case of production facilities coming online after January 2017.

3 If a plantation qualifies as a 'forest', the status of the land may be unchanged after removal of the original forest, in which case biomass from the plantation would be allowed.

$4 \mathrm{CN}$ factors are specific in terms of both time and replacement fuel. Thus, a biomass consignment would have different $\mathrm{CN}$ factors depending on whether it was used to replace natural gas, oil or coal.

\section{References}

Benndorf, R., Federici, S., Forner, C., Pena, N., Rametsteiner, E., Sanz, M. and Somogyi, Z. 2006 Including land use, land use change and forestry in future agreements: thinking outside the box. Environmental Science and Policy 10(3): 283-294.

Bird, N., Pena, N. and Zanchi, G. 2009 Work Package 2.2: a review of existing methods for carbon accounting. EC-funded project: Bioenergy, sustainability and trade-offs. Can we avoid deforestation while promoting bioenergy? (Agreement: EuropeAid/ ENV/2007/143936/TPS).

Cherubini, F., Bird, N.D., Cowie, A., Jungmeier, G., Schlamadinger, B. and Woess-Gallasch, S. 2009 Energy- and greenhouse-gas based LCA of biofuel and bioenergy systems: key issues, ranges and recommendations. Resources, Conservation and Recycling 54(8): 434-447.

Eggleston, H.S., Buendia, L., Miwa, K., Ngara, T. and Tanabe, K. (eds.) 2006 IPCC guidelines for national greenhouse gas inventories, volume 4: Agriculture, forestry, and other land use. IGES, Japan. http:// www.ipcc-nggip.iges.or.jp/public/2006gl/index.html (February 2010).

EU (European Union) 2009 Directive 2009/28/EC of the European Parliament and of the Council of 23 April 2009 on the promotion of the use of energy from renewable sources and amending and subsequently repealing Directives 2001/77/EC and 2003/30/EC. http://eurlex.europa.eu/LexUriServ/LexUriServ. do?uri= OJ:L:2009:140:0016:0062:EN:PDF (February 2010).

Farrell, A.E. and O'Hare, M. 2008 Greenhouse gas (GHG) emissions from indirect land use change. Memorandum for the California Air Resources Board Energy and Resources Group, University of California, Berkeley, CA, USA. http://www.arb.ca.gov/fuels/ Icfs/011608ucb_luc.pdf (May 2010).

Hertel, T.W., Golub, A.A., Jones, A.D., O'Hare, M., Plevin, R.J. and Kammen, D.M. 2009 Global land use and greenhouse gas emissions impacts of U.S. maize ethanol: estimating market-mediated responses. http:// ideas.repec.org/p/gta/workpp/3160.html (April 2010).

Manriquez, A.C. 2002 Carbon sequestration in the Pacific Northwest: a model. MS Thesis, University of Washington, Seattle, WA, USA. http://www.ruraltech. org/pubs/theses/manriquez (April 2010).

Pena, N. 2009 Climate change and efficient use of bioenergy and land. Joanneum Research document, for World Vision Australia.

Peters, G.P., Marland, G., Hertwich, E.G., Saikku, L., Rautiainen, A. and Kauppi, P.E. 2009 Trade, transport, and sinks extend the carbon dioxide responsibility of countries: an editorial essay. Climatic Change 97: 379-388.

Ragwitz, M., Schade, W., Breitschopf, B., Walz, R., Helfrich, N., Rathmann, M., Resch, G., Panzer, C., Faber, T. and Haas, R. 2009 EmployRES—-the impact of renewable energy policy on economic growth and employment in the European Union. Final report, contract no. TREN/ D1/474/2006.

Schlamadinger, B. and Marland, G. 1996 The role of forest and bioenergy strategies in the global carbon cycle. Biomass and Bioenergy 10(5/6): 275-300.

Schlamadinger, B. and Marland, G. 2000 Land use and global climate change. Pew Centre on Global Climate Change, Arlington, VA, USA. http://www.pewclimate. org/publications/report/land-use-global-climatechange-forests-land-management-and-kyoto-protocol (April 2010). 
Schlamadinger, B., Spitzer, J., Kohlmaier, G.H. and Lüdeke, M. 1995 Carbon balance of bioenergy from logging residues. Biomass and Bioenergy 8(4): 221-234.

Searchinger, T., Heimlich, R., Houghton, R.A., Dong, F., Elobeid, A. and Fabiosa, J. 2008 Use of U.S. croplands for biofuels increases greenhouse gases through emissions from land use change. Science 319: 1238.
Searchinger, T.D., Hamburg, S.P., Melillo, J., Chameides, W., Havlik, P., Kammen, D.M., Likens, G.E., Lubowski, R.N., Obersteiner, M., Oppenheimer, M. et al. 2009 Fixing a critical climate accounting error. Science 326: 527-528.

Sheehan, J. 2009 Sustainable biofuels: a commonsense perspective on California's approach to biofuels and global land use. Industrial Biotechnology 5(2): 93-103.

This report was produced with the financial assistance of the European Union, under the project, 'Bioenergy, sustainability and trade-offs: can we avoid deforestation while promoting bioenergy?'

European Community Contribution Agreement EuropeAid/ENV/2007/143936/TPS

The project aims to contribute to sustainable bioenergy development that benefits local people in developing countries, minimises negative impacts on local environments and rural livelihoods, and contributes to global climatechange mitigation. The project will achieve this by producing and communicating policy-relevant analyses that can inform government, corporate and civil society decision making related to bioenergy development and its effects on forests and livelihoods. The project is managed by CIFOR and implemented in collaboration with the Council on Scientific and Industrial Research, South Africa, Joanneum Research, Austria, the Universidad Autónoma de México, and the Stockholm Environment Institute, Sweden. The views expressed in this brief can in no way be taken to reflect the official opinion of the European Union. 